\title{
Synthesis and Characterization of Novel Chiral [(NHC)Au(I)Cl] Complexes: Featuring ortho-Biphenyl Substituents
}

\author{
Michael R. Holmes ${ }^{\mathrm{a}}$, John F. Manganaro ${ }^{\mathrm{a}}$, Charles L. Barnes ${ }^{\mathrm{b}}$, Benjamin W. Gung ${ }^{\mathrm{a} *}$ \\ ${ }^{a}$ Department of Chemistry \& Biochemistry, Miami University, Oxford, Ohio 45056 \\ ${ }^{\mathrm{b}}$ Elmer O. Schlemper X-Ray Diffraction Center, University of Missouri-Columbia, Columbia, MO 65211 United States.
}

Received: The date will be inserted once the manuscript is accepted.

\begin{abstract}
A series of new chiral [(NHC)Au(I)Cl] are synthesized. The chiral NHC ligands feature pairs of ortho-biphenyl groups. The distal phenyl groups of the biphenyl substituents are varied from simple phenyl, 3,5-dimethylphenyl, to 3,5-di-t-butylphenyl. $\mathrm{X}$-Ray structure analysis were performed for two such $[(\mathrm{NHC}) \mathrm{Au}(\mathrm{I}) \mathrm{Cl}]$ complexes. High percent buried volumes were calculated for two novel chiral [(NHC)Au(I)Cl]complexes whose structure were solved by an X-ray analysis. The rotational motion in the biphenyl group is slow on the NMR time scale. Rotational barriers were determined using WINDNMR for two of the chiral gold complexes.
\end{abstract}

Key words: NHC ligands, gold (I) complexes, ligand dynamics, percent buried volumes, rotational barrier.

\section{Introduction}

The field of the N-heterocyclic (NHC) ligands in homogeneous catalysis has significantly expanded in the last two decades due to many advantages in their stability and structural variability.[1-3] Chiral NHC ligands are being developed to replace chiral phosphines for several transition metal complexes.[4-7] As shown in Figure 1, NHC ligands 1-3 with saturated imidazole ring allow for two chiral centers in the ring, and the "gearing" effect transmits the asymmetry to the coordination site.[4-7]<smiles>[Al]N1CN([Al])[C@H](c2ccccc2)C1c1ccccc1</smiles><smiles></smiles>

$1 \mathrm{Ar}=$ substituted phenyl

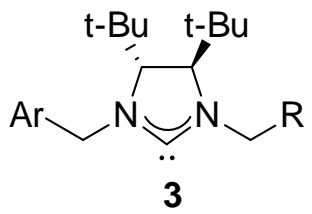

2

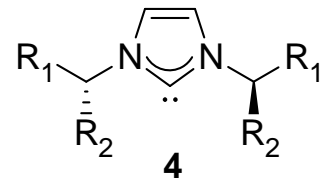

a: $R_{1}=$ Naph, $R_{2}=M e$

b: $R_{1}=$ Mes, $R_{2}=E t$

c: $R_{1}=A r, R_{2}=i P r, t B u$

Figure 1. Representative chiral N-heterocyclic carbenes previously reported.

One of the earliest reported chiral NHCs has a core structure of imidazole (4) with varying substituents of $\mathrm{R}_{1}$ and $\mathrm{R}_{2}$. Herrmann and coworkers prepared the chiral NHC $\mathbf{4 a}$ for a Rhodium complex.[8] Later Alexakis and coworkers were able to extend the usage to $\mathrm{Cu}$-catalyzed conjugate additions with similar chiral NHCs.[9] Saito reported a three component Ni-catalyzed reaction with chiral NHC ligand $\mathbf{4 b}$.[10] At the same time, Kundig found that $\mathbf{4 c}$ with a $t$-butyl group as the substituent $\mathrm{R}_{2}$ and variations at the aryl substituent $\mathrm{R}_{1}$ provided an effective chiral NHC ligand for a Pd-catalyzed C-H activation reaction.[11]

* Corresponding author.

E-mail addresses: gungbw@miamioh.edu (B. W. Gung). 
During our study of intramolecular [4+3] cycloadditions, we discovered that gold complexes with NHC ligands are most suitable for such transformations.[12] Gold complexes with chiral NHC ligands are relatively new and have only begun to appear recently. The tendency of gold(I) to form linear twocoordinate complexes makes the design of new chiral NHC ligands limited to mono dentate NHCs. The two coordination sites allow one mono dentate ligand and one coordination site for substrate. This limitation increases the challenge for the development of enantioselective catalysts. Our initial attempt in 2010 at the preparation of chiral NHC ligands for Au(I) complexes (Figure 2, 5 and 6) revealed the importance of the ligand structure on gold complex stability.[13] Complexes 5 and $\mathbf{6}$ were activated for the cyclopropanation reactions of propargyl esters upon treatment with a silver salt. However, their thermal stability is much less robust compared to Nolan's achiral complex Au(IPr)Cl.[14] The lesson we learned was that the design of chiral NHC ligands for preparing gold catalysts must take into account the steric bulk of the ligand to protect the gold atom. Some of the more successful chiral $[(\mathrm{NHC}) \mathrm{Au}(\mathrm{I}) \mathrm{Cl}]$ complexes are from the groups of Tomioka and Kundig, independently.[15, 16]
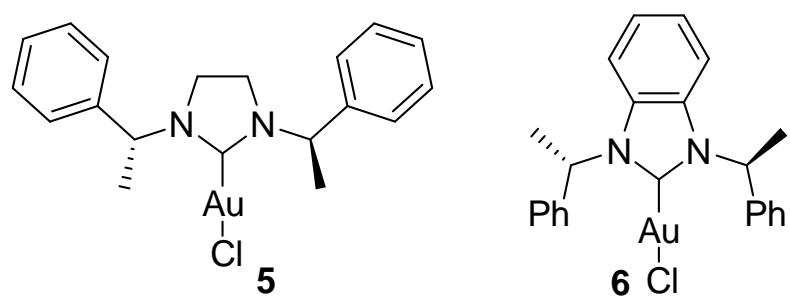

Figure 2. Thermally labile chiral [(NHC)Au(I)Cl] complexes previously reported by us.[13]

Our continued interest in improving NHC ligands so that it will be suitable for $\mathrm{Au}(\mathrm{I})$ catalysis with cycloaddition reactions led us to choose the unsaturated $\mathrm{NHC}$ as the core structure (4). We surmised that the substituents on nitrogen atoms can be further improved so that a strong steric bias would occur when coordinated to Au(I). Thus far the groups of Alexakis,[17] Saito,[10] and Kundig[18] have modified NHC 4 by changing the alkyl and aryl groups with varying degree of success. The alkyl group variations include methyl, ethyl, isopropyl, and t-butyl, while the aryl groups employed so far were phenyl, naphthyl, mesityl, and 2-methylphenyl and 2-methoxyphenyl groups.[19] Kundig's group did most work in this area including a chiral ligand with a $p$-biphenyl substituent.[16] The difference between the chiral NHC reported in this study and the one example from Kundig's group is the position where the biphenyl attaches to the chiral center. We have ortho-biphenyl substitution while one example of a parabiphenyl was reported previously.

\section{Results and discussion}

In our design, both stability and steric bias are aimed for the NHC ligand. Thus both steric and electronic effects need to be considered. The important key element in the new design is a bulky obiphenyl group as the aryl substituent. Buchwald and co-workers were the first to use a biphenyl $o$-(ditert-butylphosphino) palladium complex in the catalysis of Suzuki coupling reactions.[20, 21] The same biphenyl phosphino ligand was then used for Au catalysts by Echavarren.[22] Favorable metal-pi interactions have been reported in transition metal complexes.[23, 24] The ligand containing the obiphenyl moiety appears to provide a favorable scaffold for such stabilizing interactions. To the best of our knowledge, none of the effective $\mathrm{N}$-heterocyclic carbene ligands reported so far has incorporated the o-biphenyl group.[7, 25] As depicted in Scheme 1, the ortho aryl groups in two ligand series are further 
adorned with 3,5-dialkyl (methyl or t-butyl) group. The alkyl groups $(\mathrm{R})$ at the stereocenter vary in size from a methyl group to an isopropyl group. Using this modular approach, a total of nine chiral amines (11a-12c, and 15a-c) with unique structures are prepared. We employed the known chiral amines $\mathbf{7}$ and $\mathbf{8}$ as the starting materials for the desired amines 11a-12c, Scheme 1.[26, 27] The protection of the amino function in $\mathbf{7}$ and $\mathbf{8}$ using t-butoxycarbonyl (t-BOC) enabled Suzuki coupling with three different aryl boronic acids. After Suzuki coupling, the removal of the t-BOC with $\mathrm{CF}_{3} \mathrm{CO}_{2} \mathrm{H}$ produced chiral amines 11a-12c.

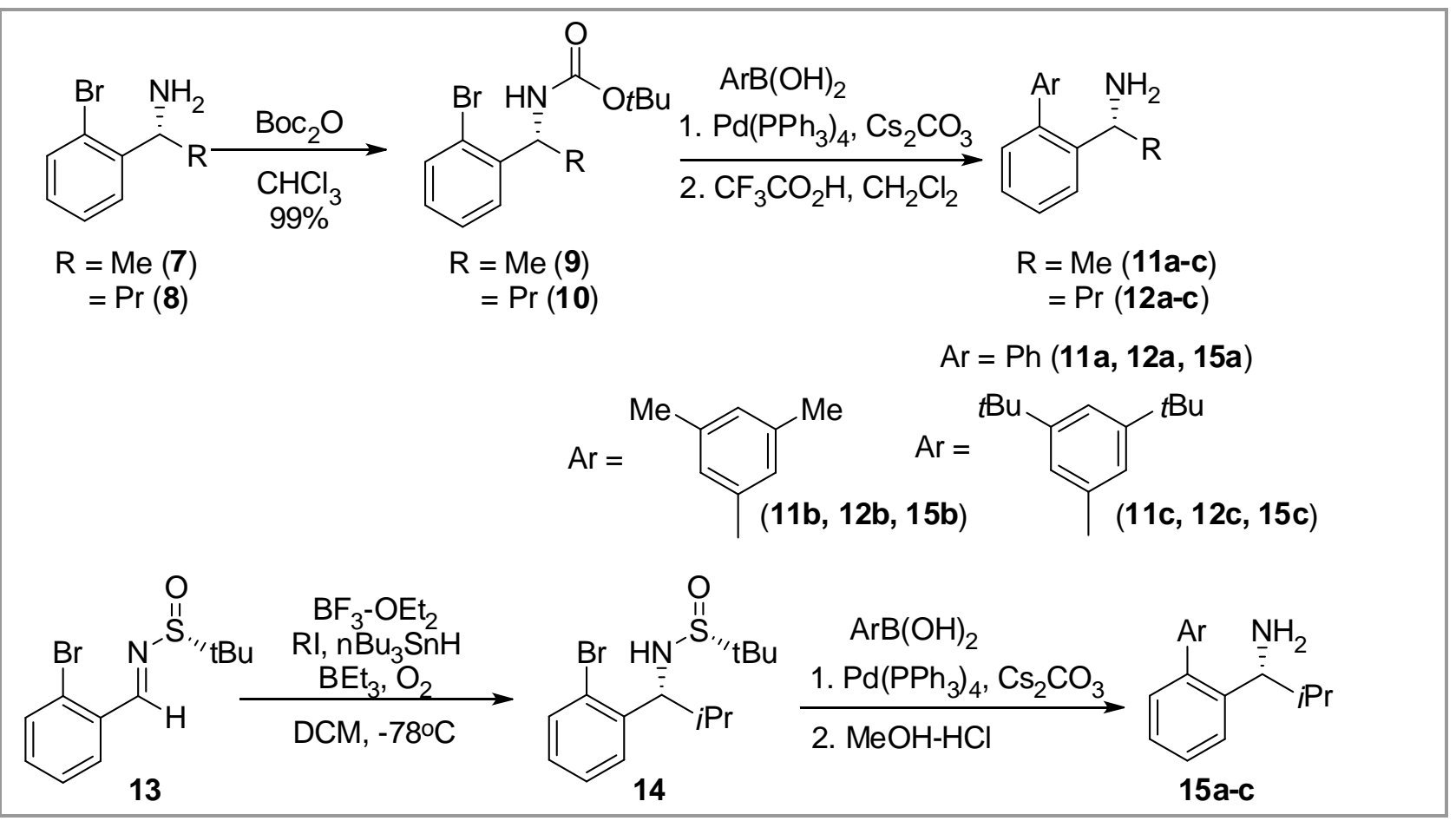

Scheme 1 Synthesis of chiral amines 11a-12c and 15a-c with ortho-biphenyl groups via Suzuki coupling reactions.

Chiral amines 15a-c were prepared efficiently through intermolecular alkyl radical addition starting from the known sulfonamide 13, Scheme 1.[28, 29] We were pleased to observe smooth Suzuki coupling reactions of the sulfonamide 14 with different $\operatorname{ArB}(\mathrm{OH})_{2}$, which eliminated the need of using an amino protecting group. The sulfinyl group of $\mathbf{1 4}$ was removed with acidic methanol after Suzuki coupling to afford chiral amines 15a-c.

The chiral $\mathrm{Au}(\mathrm{I})$ complexes 19a-21c are prepared as shown in Scheme 2 following the improved procedure by Nolan and co-workers.[30] Briefly the chiral amines $(\mathbf{1 1}, \mathbf{1 2}$, or 15) are converted to diimine intermediates by treating with glyoxal and formic acid. The resulting diimines were immediately allowed to react with chloromethyl ethyl ether to produce the imidazolium chlorides (16a-18c). The chiral NHCgold(I) complexes (19a-21c) were obtained by stirring the imidazolium chloride with $\mathrm{Au}\left[\mathrm{S}(\mathrm{Me})_{2}\right] \mathrm{Cl}$ in acetone in the presence of $\mathrm{K}_{2} \mathrm{CO}_{3}$. The gold(I) complexes of 19a-21c are stable and can be purified by column chromatograph. All of their structures are carefully studied by ${ }^{1} \mathrm{H}$ and ${ }^{13} \mathrm{C}$ NMR spectroscopy. 


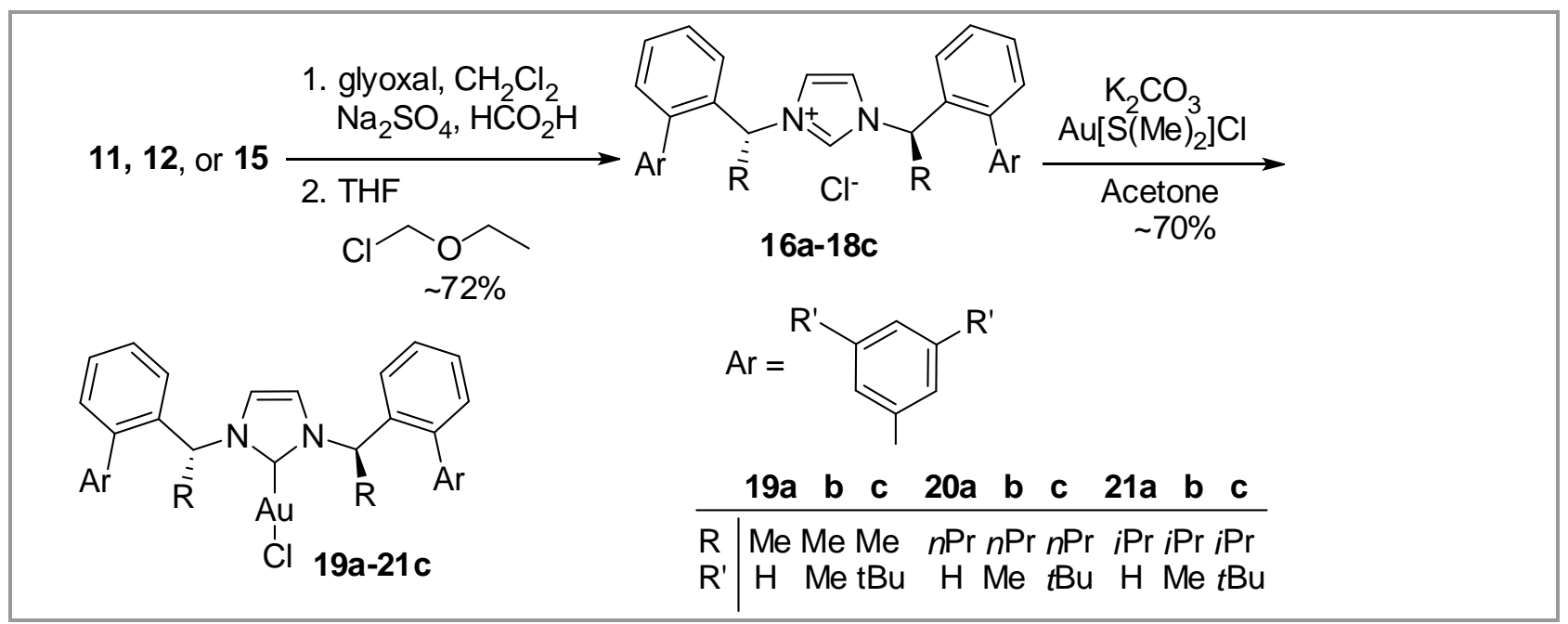

Scheme 2 Synthesis of Au(I) complexes 19a-21c with variations at the alkyl (R) and the aryl (Ar) groups.

For comparison purpose, we prepared the $[(\mathrm{ADC}) \mathrm{Au}(\mathrm{I}) \mathrm{Cl}]$ complex $(\mathbf{2 3})$ from the known isonitrile 22[31] as shown in eq. 1.[32] An X-ray structure analysis of $\mathbf{2 3}$ is shown in Figure 3. The key structural data for the $[(\mathrm{ADC}) \mathrm{Au}(\mathrm{I}) \mathrm{Cl}]$ complex $(\mathbf{2 3})$ are compiled in Table 1 along with the $\mathrm{NHC}-\mathrm{AuCl}$ complexes.

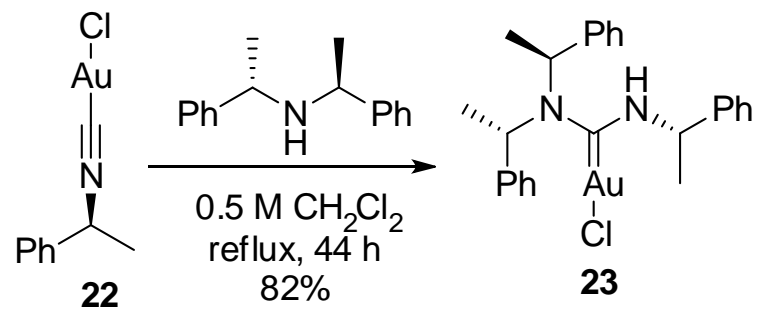

X-Ray quality crystals were also obtained for two of the NHC complexes (19a and 21b) when the purified $[\mathrm{NHCAu}(\mathrm{I}) \mathrm{Cl}]$ complexes were dissolved in a minimal amount of dichloromethane in a long test tube and hexanes were carefully layered on top of the solution. ORTEP representations of [NHC][AuCl] (19a and 21b) and [ADC][AuCl] (23) are presented in Figure 3.

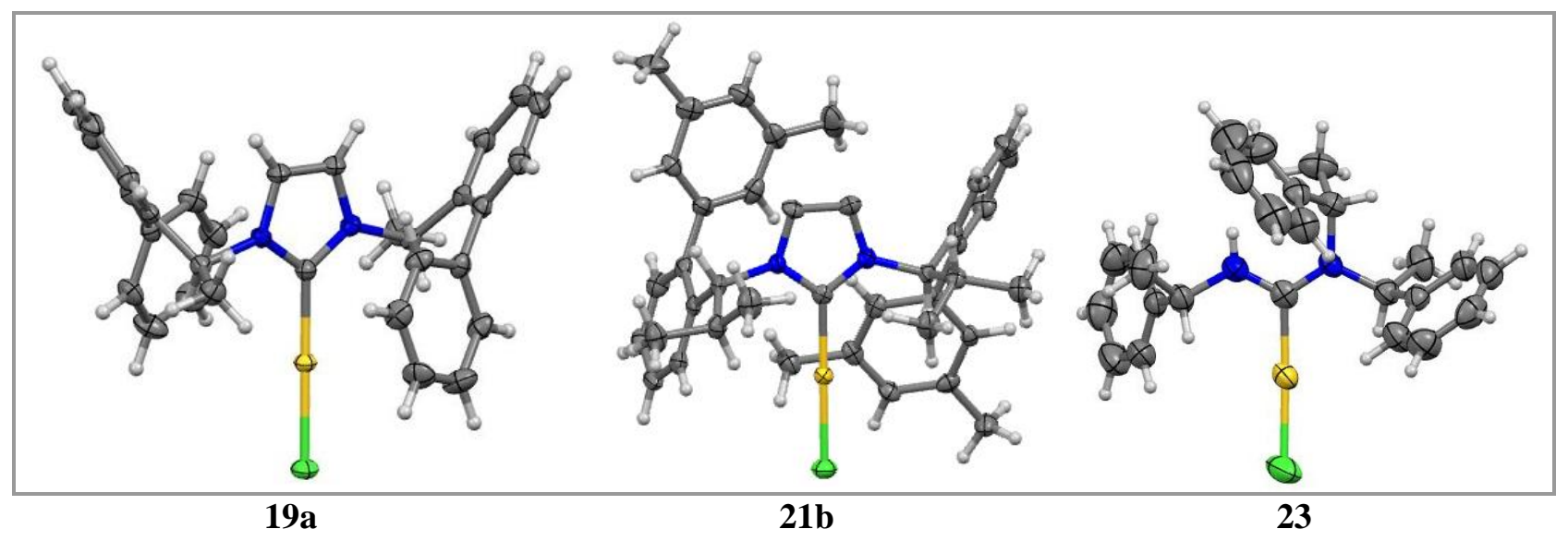

Figure 3. ORTEP representation of $[\mathrm{NHC}][\mathrm{AuCl}](\mathbf{1 9 a}$ and 21b) and $[\mathrm{ADC}][\mathrm{AuCl}](\mathbf{2 3})$. 
We are pleased to find that the new chiral gold(I) complexes (19a-21c) can produce catalysts that are much more stable than those we have previously reported, i.e., catalysts prepared from complexes $\mathbf{5}$ and $\mathbf{6}$ or 23. To avoid unpredictable effects of the silver salt, we usually try to minimize the presence of the silver salt by protecting $\mathrm{Au}(\mathrm{I})$ with benzonitrile after abstraction of the chloride with $\mathrm{AgSbF}_{6}$ and filtering off the resulting $\mathrm{AgCl}$, eq. 2.[12, 33]

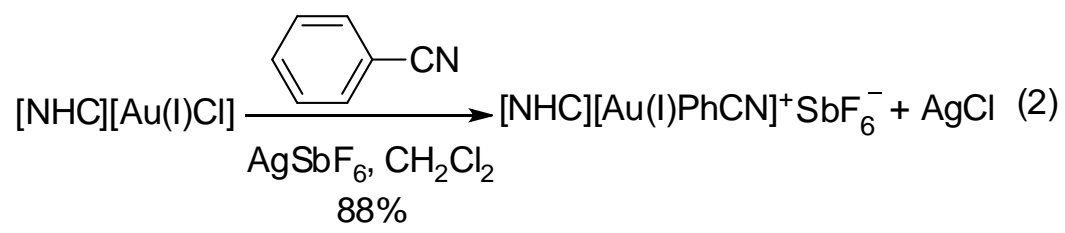

Upon the chloride abstraction by using $\mathrm{AgSbF}_{6}$, the cationic $\mathrm{Au}(\mathrm{I})$ complexes are active catalysts and are susceptible to disproportionation reaction leading to "gold mirroring".[13] However the complexes prepared in this study (Scheme 2) appear to be stable for days after the chloride abstraction treatment as shown in eq. 2. In order to compare their thermal stability, variable temperature NMR experiments were performed on the two different $\mathrm{Au}(\mathrm{I})$ complexes, the $[\mathrm{NHC}]\left[\mathrm{Au}(\mathrm{I}) \mathrm{PhCN}^{+} \mathrm{SbF}_{6}^{-}\right.$ complex prepared from $\mathbf{2 1 b}$, and the $[\mathrm{ADC}]\left[\mathrm{Au}(\mathrm{I}) \mathrm{PhCN}^{+} \mathrm{SbF}_{6}^{-}\right.$complex prepared from 23. Each gold complex was treated with an equal molar amount of $\mathrm{AgSbF}_{6}$ and $\mathrm{PhCN}$ in $\mathrm{CDCl}_{3}$ and stirred at room temperature for $15 \mathrm{~min}$, eq. (2).

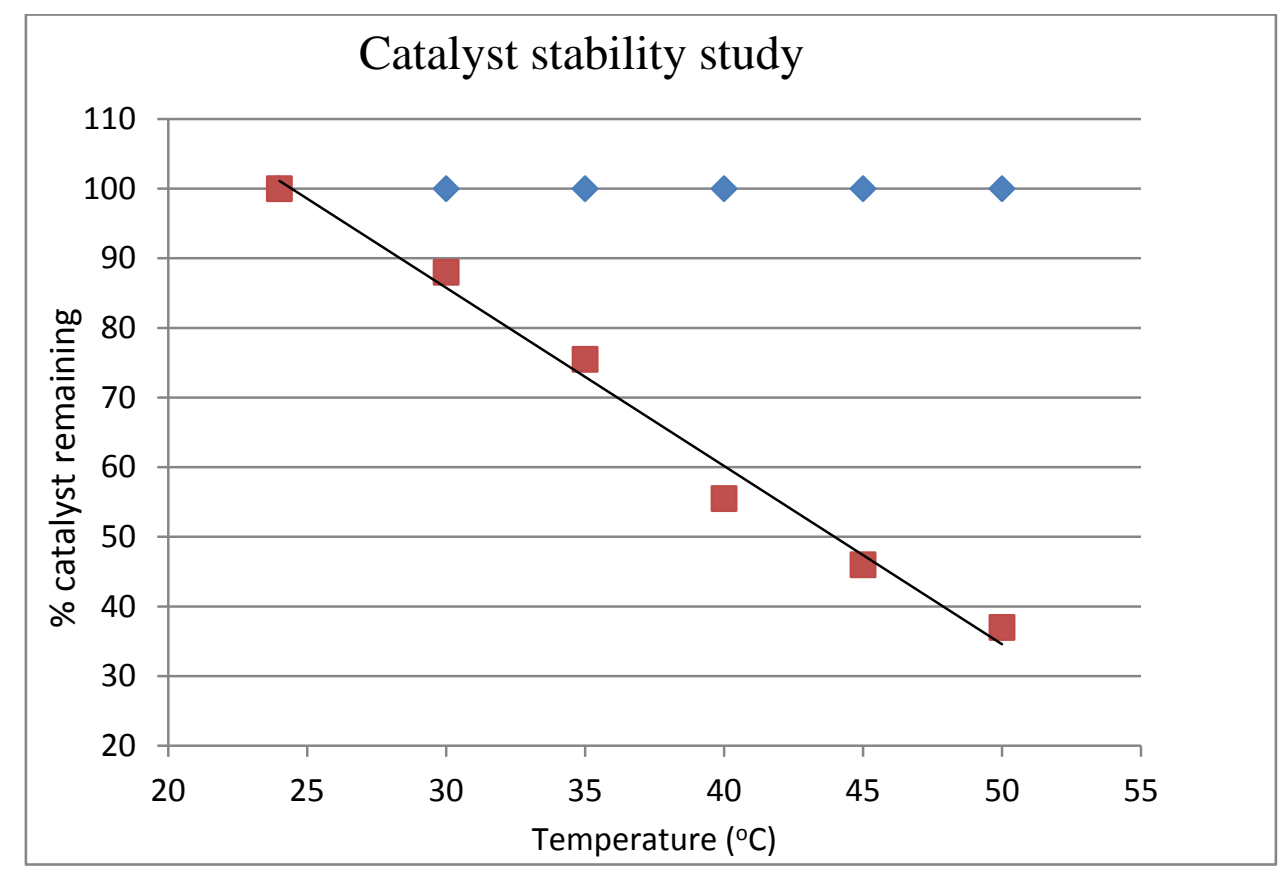

Figure 4. Catalyst stability study: ( $\diamond$ catalyst prepared from $\mathbf{2 1 b},(\boldsymbol{\square})$ catalyst prepared from 23.

The resulting suspension was filtered and the filtrate was loaded into an NMR tube and the ${ }^{1} \mathrm{H}$ NMR spectra were recorded at $30 \mathrm{~min}$ interval from room temperature to $50{ }^{\circ} \mathrm{C}$. The ${ }^{1} \mathrm{H}$ NMR spectra of the cationic $\mathrm{Au}(\mathrm{I})$ complexes were recorded from rt to $50^{\circ} \mathrm{C}$ during a five hour time period. $\mathrm{The}^{\mathrm{CDCl}} \mathrm{CD}_{3}$ 
we used was purchased and used as received. The one equivalent of PhCN serves to stabilize the cationic gold complex in solution. The cationic catalyst prepared from $\mathbf{2 1 b}$ showed no signs of change from room temperature to $50{ }^{\circ} \mathrm{C}$ and from the first to the last spectrum taken during the 5 hours of time, Figure 4 .

For catalyst prepared from $\mathbf{2 3}$, it was convenient to monitor the ortho protons on one of the phenyl groups during the NMR study because of their up-field chemical shifts. A steady decrease of the peak at $6.6 \mathrm{ppm}$ was observed as the temperature rises. At the conclusion of the experiments for catalyst 23, a gold mirror was deposited onto the bottom of the NMR tube. Thus the variable temperature NMR experiments carried out with the two gold complexes support the hypothesis that the o-biphenyl substituent protect the cationic $\mathrm{Au}(\mathrm{I})$ catalyst in the $[\mathrm{NHC}][\mathrm{Au}(\mathrm{I}) \mathrm{PhCN}]^{+} \mathrm{SbF}_{6}{ }^{-}$complex prepared from $21 b$.

It is interesting and informative to compare their properties with what we have reported previously in order to understand the important elements in $[(\mathrm{NHC}) \mathrm{Au}(\mathrm{I}) \mathrm{Cl}]$ structures. Both steric and electronic effects of the ligands in metal complexes play a role in the property of the complex. In gold(I) complexes, steric effects appear to be extremely important. One likely reason is that the steric bulk of the ligands can protect the Au atom from disproportionation reaction, hence leading to improved thermal stability. The evaluation of ligand steric effects has been developed for both phosphines and NHCs. Tertiary phosphine ligands are commonly classified using the Tolman cone model for steric effects around metal center.[34] Nolan and Cavallo proposed an alternate model, initially intended to measure the NHC steric bulk. $[35,36]$ The "percent buried volume", $\% V_{\text {Bur }}$ gives a measure of the space occupied by an organometallic ligand in the first coordination sphere of the metal center. The sphere has a defined radius and has the metal center at the core. $\% V_{\text {Bur }}$ is calculated using crystallographic data. A website named SambVca has been set up for the calculations of the percent buried volume.[37] By definition the bulkier a specific ligand is, the larger the amount of the sphere that will be occupied by the ligand, i.e. greater $\% V_{\text {Bur. }}$. The relative significance of $\% V_{\text {bur }}$ was found to be more important in gold and silver complexes than in $[\mathrm{PdCl}(\mathrm{NHC})($ allyl)] complexes.[38] The linear geometry of the silver and gold complexes was suggested to be at the origin of these differences.

Table 1. Comparison of $\mathrm{Au}-\mathrm{C}$ bond length, $\mathrm{C}-\mathrm{Au}-\mathrm{Cl}$ bond angle and $\% \mathrm{~V}_{\mathrm{Bur}}$ for [ $\left.\mathrm{LAu}(\mathrm{I}) \mathrm{Cl}\right]$ complexes.

\begin{tabular}{|c|c|c|c|c|c|}
\hline Complex & $\begin{array}{l}\text { Au-C1 }(\AA) \\
\text { Bond length }\end{array}$ & $\begin{array}{l}\mathrm{C}-\mathrm{Au}-\mathrm{Cl}\left({ }^{\circ}\right) \\
\text { Bond angle }\end{array}$ & $\begin{array}{l}\mathrm{C}(\mathrm{Ar})--\mathrm{Au}(\AA) \\
\text { Close contact }\end{array}$ & $\begin{array}{c}\angle_{\mathrm{CCCC}}\left(^{\circ}\right) \\
\text { Aryl-aryl torsion }\end{array}$ & $\% \mathrm{~V}_{\text {Bur }}^{\mathrm{a}}$ \\
\hline $\mathrm{IPrAuCl}^{\mathrm{b}}$ & $1.942(3)$ & $177.0(4)$ & na & na & 44.5 \\
\hline $5^{c}$ & $1.998(3)$ & 178.1(4) & na & na & 36.4 \\
\hline $6^{c}$ & $2.003(3)$ & $179.5(4)$ & na & na & 29.4 \\
\hline $\mathbf{2 3}^{\mathrm{d}}$ & $2.004(3)$ & $177.9(4)$ & 3.73 & na & 36.7 \\
\hline 19a & $1.979(3)$ & $180.0(4)$ & 4.00 & 65.7 & 44.6 \\
\hline 21b & $1.989(3)$ & 179.1(4) & 3.36 & 66.8 & 53.8 \\
\hline
\end{tabular}

${ }^{\text {a }}$ Parameters used for SambVca calculations: sphere radius, 3.50 A; Au-C1, $2.00 \AA$ A; mesh spacing, 0.10;

Bondi radius, 1.17. $\mathrm{H}$ atoms are excluded.

${ }^{b}$ Taken from Ref. [36]. ${ }^{c}$ Work reported in Ref. [13]. ${ }^{d}$ Taken from Ref.[32] 
The values of $\% \mathrm{~V}_{\mathrm{Bur}}$ were calculated for $\mathrm{Au}(\mathrm{I})$ complexes $5, \mathbf{6}, \mathbf{1 9} \mathbf{a}, \mathbf{2 1} \mathbf{b}$ and 23 and comparison is made to the steric demanding complex IPrAuCl.[39] The exact values of the $\% \mathrm{~V}_{\mathrm{Bur}}$ also depend on the choice of several parameters: the sphere radius defined for the metal complex, the metal ligand bond distance, and a scale constant (bondi radius). In order to obtain consistent results, one should be careful to keep the same set of variables for all calculations. We employed the standard constant set reported by Nolan and the resulting percent buried volumes calculated are shown in Table 1, which include all gold(I) complexes that we have crystallographic data.

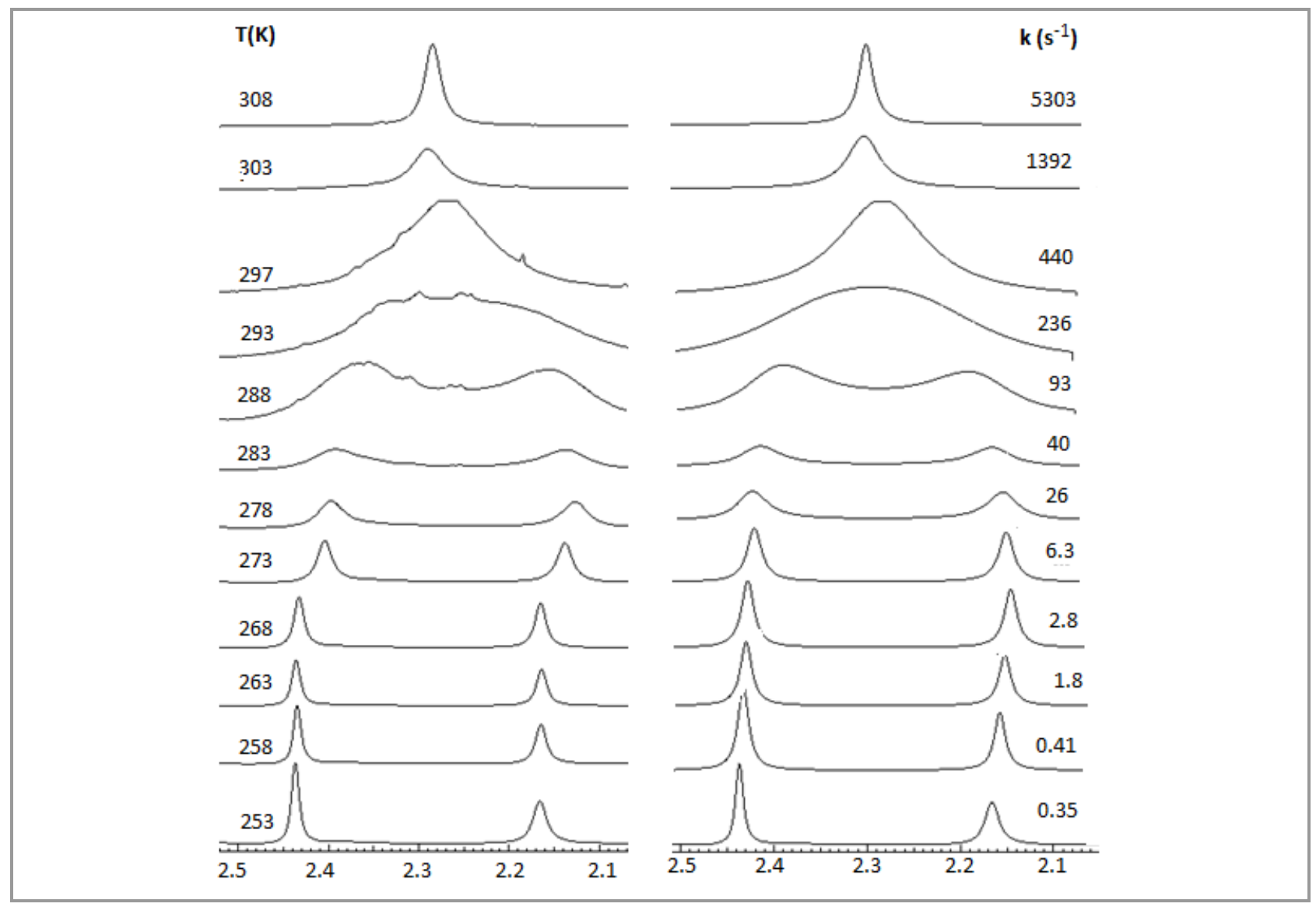

Figure 5. Left: temperature-dependent NMR signals (300 $\mathrm{MHz}$ in $\mathrm{CDCl}_{3}$ ) of the 3,5-dimethyl protons on the distal phenyl group of compound $\mathbf{2 1 b}$. Right: computer simulations using a line shape analysis program (WINDNMR)[40] with the rate constants reported.

There is a remarkable correlation between the calculated $\% \mathrm{~V}_{\mathrm{Bur}}$ and the $\mathrm{Au}(\mathrm{I})$ catalyst stability. Nolan's IPrAu(I)Cl complex has a value of 44.5 and is known to generate an extraordinarily stable catalyst. Our previously reported complex 6 has the smallest $\% \mathrm{~V}_{\text {Bur }}$ value of 29.4 in Table 1 and it was the least stable catalyst. Once the chloride is removed, complex 6 immediately decomposed about 50\% when the NMR sample was run.[13] Complex 5 has a percent buried volume of 36.4 and it showed more stability than 6, but it also decomposed within a few hours after activating with $\mathrm{AgSbF}_{6}$.[13] The ADC complex $\mathbf{2 3}$ has a similar $\% \mathrm{~V}_{\text {Bur }}$ to $\mathbf{5}$ and it showed very similar stability as a catalyst.[32] 


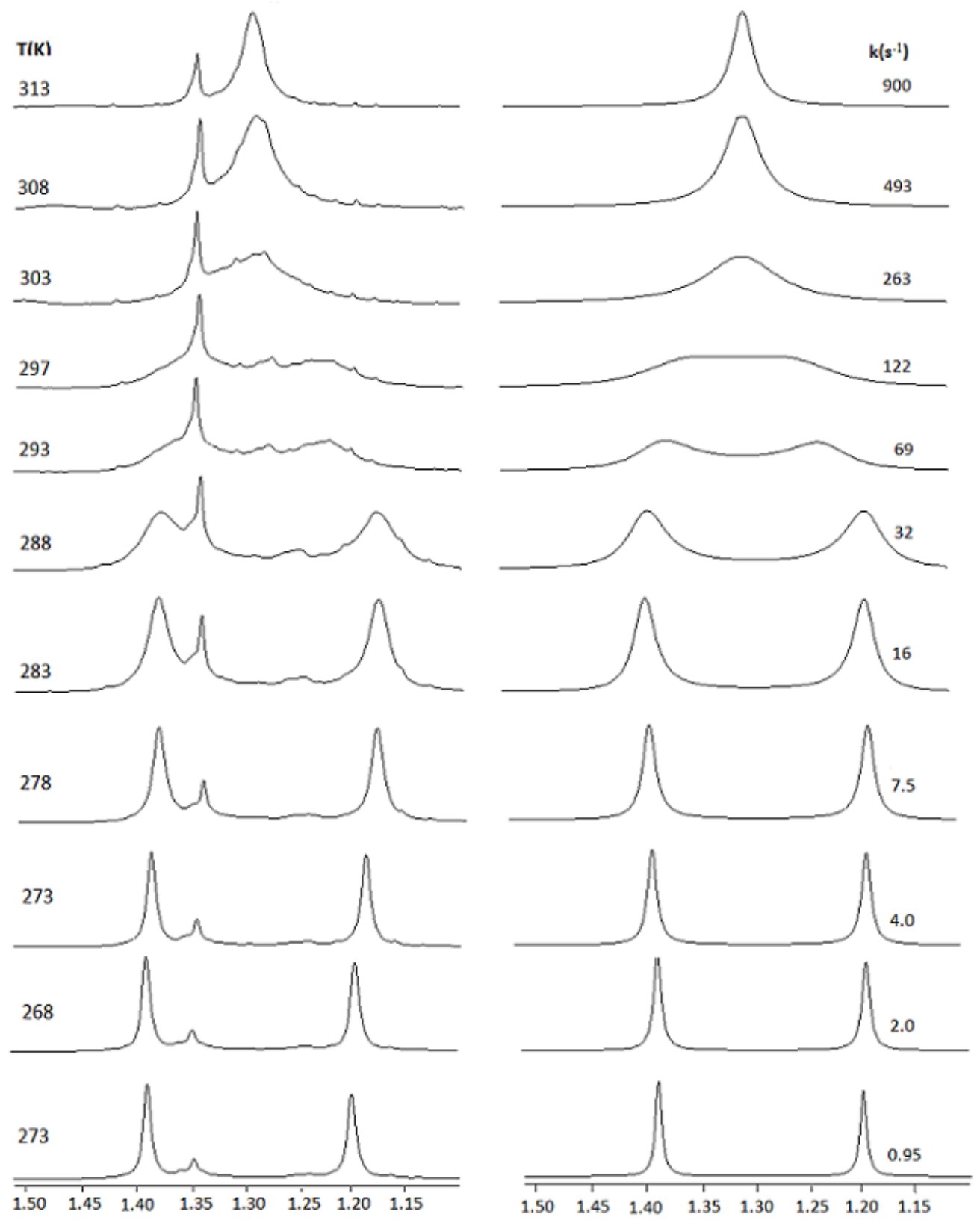

Figure 6. Left: temperature-dependent NMR signals ( $300 \mathrm{MHz}$ in $\mathrm{CDCl}_{3}$ ) of the 3,5-di-t-butyl protons on the distal phenyl group of compound 21c. Right: computer simulations using a line shape analysis program (WINDNMR)[40] with the rate constants reported.

We are pleased to see the percent buried volumes calculated for the new complexes 19a and 21b are substantially larger. The gold(I) complex 19a have a calculated $\% \mathrm{~V}_{\text {Bur }}$ of 44.6 , almost identical to that of $\operatorname{IPrAu}(\mathrm{I}) \mathrm{Cl}$. The complex $\mathbf{2 1 b}$ has a $\% \mathrm{~V}_{\text {bur }}$ of 53.8, which is greater than the very bulky [IPr*Au(I)Cl] complex $\left(\% \mathrm{~V}_{\text {bur }}=50.4\right)$ reported by Nolan.[41] We proceeded to remove the chloride from complexes 19a and $21 \mathbf{b}$ according to eq. 1 and observed no significant change in their ${ }^{1} \mathrm{H}$ NMR spectra after several days . 
The large percent buried volumes for the new gold complexes may be attributed to the o-biphenyl group. The biphenyl substituents through their ortho attachment to the stereogenic carbons place the distal phenyl group inside or near the first coordination sphere centered by the gold atom. Crystal packing forces also contribute to the solid state conformations. The rotational flexibility of the biphenyl axis allows the distal phenyl group to wrap around the Au atom. This analysis is supported by the X-ray structure (although the solution structure may differ from the solid state structure) and by the observation that the rotation around the biphenyl axis is slowed to such a degree that coalescence was observed for complexes 21b and 21c at room temperature, rather than at much lower temperatures. Usually monosubstituted biphenyls have free rotation at room temperature on the NMR time scale.[42] However in these complexes the hindrance to free rotation may arise from steric interactions involving the 3,5-dialkyl substituents and the Au-Cl moiety of the complex. The distal phenyl groups are right next to the gold atom and any substituents on the phenyl group could cause steric interactions when rotating around the biphenyl axis.

Table 2. Rate constants for Compounds 21b and 21c at Different Temperatures obtained using WINDNMR.[40]

\begin{tabular}{lll}
\hline $\mathrm{T}(\mathrm{K})^{\mathrm{a}}$ & $\mathrm{k}_{\mathrm{r}}(\mathbf{2 1 b})$ & $\mathrm{k}_{\mathrm{r}}(\mathbf{2 1 c})$ \\
\hline 323 & $3.37 \times 10^{5}$ & 2606 \\
\hline 318 & $1.71 \times 10^{5}$ & 1678 \\
\hline 313 & $7.11 \times 10^{4}$ & 900 \\
\hline 308 & 5303 & 493 \\
\hline 303 & 1392 & 263 \\
\hline 297 & 440 & 122 \\
\hline 293 & 236 & 69 \\
\hline 288 & 93 & 32 \\
\hline 283 & 40 & 16 \\
\hline 278 & 26 & 7.5 \\
\hline 273 & 6.3 & 4.0 \\
\hline 268 & 2.8 & 2.0 \\
\hline 263 & 1.8 & 0.95 \\
\hline 258 & 0.41 & \\
\hline 253 & 0.35 & \\
\hline
\end{tabular}

${ }^{a}$ Temperature was not calibrated and was recorded as shown on the instrument dial.

In order to understand the o-biphenyl ligand center C-C bond rotational dynamics in the gold complexes, we performed NMR spectroscopic study for complexes $\mathbf{2 1 b}$ and $\mathbf{2 1 c}$ at different temperatures, Figure 4. Variable temperature NMR experiments were performed from -20 to $50{ }^{\circ} \mathrm{C}$ with deuterated 
chloroform as solvent. At around $5{ }^{\circ} \mathrm{C}$, the rotation around the biphenyl axis becomes slow enough that the signals for the two methyl groups decoalesce, with one at $\sim 2.15 \mathrm{ppm}$ and the other at $\sim 2.4 \mathrm{ppm}$, Figure 4. At around $30^{\circ} \mathrm{C}$, the rotation around the biphenyl axis becomes fast enough that the signals for the two methyl groups become a single peak centered at $\sim 2.28$ ppm, Figure 4 .

According to the thermodynamic equation $\Delta \mathrm{G}^{\ddagger}=\Delta \mathrm{H}^{\ddagger}-\mathrm{T} \Delta \mathrm{S}^{\ddagger}$ and transition state theory, [43] enthalpies, entropies and free energies of activation are related to rate constants by the following equations:

$$
\begin{aligned}
& \mathrm{k}_{\mathrm{r}}=\mathrm{k}_{\mathrm{B}} \mathrm{T} / \mathrm{h} \mathrm{e}^{\Delta \mathrm{G} \sharp / \mathrm{RT}}=\left(\mathrm{k}_{\mathrm{B}} \mathrm{T} / \mathrm{h}\right) \mathrm{e}^{-\Delta \mathrm{H} \ddagger / \mathrm{RT}} \mathrm{e}^{\Delta \mathrm{S} \ddagger / \mathrm{R}} \\
& \Delta \mathrm{G}^{\ddagger}=-\mathrm{RT} \ln \left(\mathrm{k}_{\mathrm{r}} \mathrm{h} / \mathrm{k}_{\mathrm{B}} \mathrm{T}\right)=1.987 \mathrm{cal} \mathrm{mol}{ }^{-1} \mathrm{~T}\left(23.76+\ln \left(\mathrm{T} / \mathrm{k}_{\mathrm{r}}\right)\right)
\end{aligned}
$$

where $\mathrm{k}_{\mathrm{r}}=$ rate constant, $\mathrm{k}_{\mathrm{B}}=$ Boltzman constant $1.380 \times 10^{-23}, \mathrm{~T}=$ Temperature in $\mathrm{K}, \mathrm{h}=$ Planck's constant $6.626 \times 10^{-34}, \mathrm{R}=$ gas constant $1.987 \mathrm{cal} \mathrm{deg}^{-1} \mathrm{~mol}^{-1}, \ln \left(\mathrm{h} / \mathrm{k}_{\mathrm{B}}\right)=23.76$.

The free energies of activation $\left(\Delta \mathrm{G}^{\ddagger}\right)$ are calculated from the rate constants (eq. 4 and Table 2), which are obtained from the simulations performed using WINDNMR (see Figure 5 and 6). Plotting the calculated $\Delta \mathrm{G}^{\star}$ vs. T, enthalpy and entropy of activation can be estimated, Figure 7 and Table 3 .

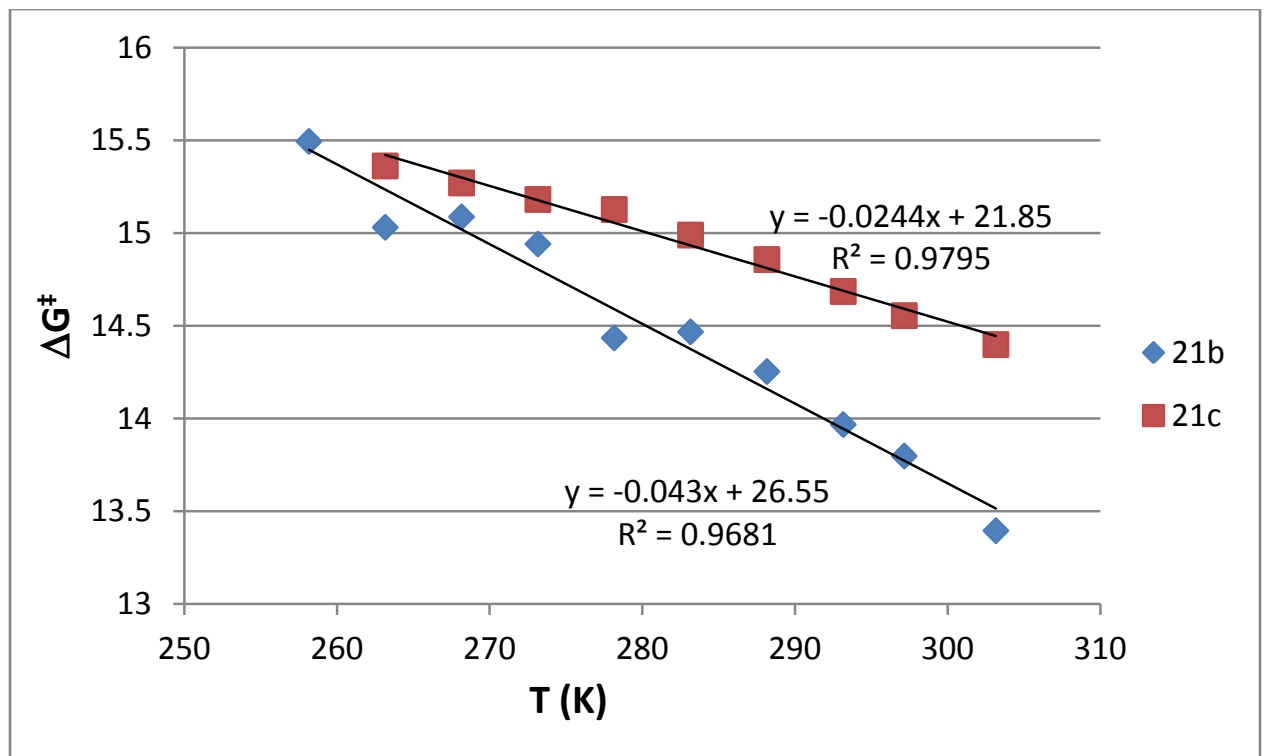

Figure 7. The plot of $\Delta \mathrm{G}^{\dagger}$ vs. T for center C-C bond rotation of the biphenyl substituent of complexes $\mathbf{2 1 b}$ and 21c.

The observed biphenyl center C-C bond rotational barriers for the complexes $\mathbf{2 1 b}$ and $\mathbf{2 1 c}$ are 14.7 and $13.8 \mathrm{kcal} / \mathrm{mol}$, respectively and the rotational barrier has a significant entropy term. The fact that both complexes have a positive and substantial rotational entropy of activation indicate the biphenyl group experiences more than a simple rotational barrier because simple rotations have small and negative entropy of activation.[44] Our current interpretation for the positive entropy of activation is that the 
substituents on the distal phenyl group have restricted movements in the ground state due to steric interactions with the $\mathrm{Au}-\mathrm{Cl}$ moiety.

Table 3. Activation parameters for center $\mathrm{C}-\mathrm{C}$ bond rotation of the biphenyl substituent of complexes 21b and 21c in $\mathrm{CDCl}_{3}$

\begin{tabular}{lcccc}
\hline Complex $^{\mathrm{a}}$ & $\begin{array}{l}\Delta \mathrm{G}^{\ddagger}(\text { rotation }) \\
(\mathrm{kcal} / \mathrm{mol})\end{array}$ & $\begin{array}{l}\Delta \mathrm{H}^{\ddagger}(\text { rotation }) \\
(\mathrm{kcal} / \mathrm{mol})\end{array}$ & $\begin{array}{l}\Delta \mathrm{S}^{\ddagger} \text { (rotation) } \\
(\mathrm{cal} / \mathrm{mol} \mathrm{K})\end{array}$ & $\begin{array}{l}\text { Coalescence } \\
\text { Temp }(\mathrm{K})\end{array}$ \\
\hline 21b & $14.0(1)$ & $26.6(0.8)$ & $43.0(3)$ & 293 \\
\hline 21c & $14.6(1)$ & $21.9(0.4)$ & $24.4(2)$ & 297 \\
\hline
\end{tabular}

a The standard errors for the intercept and slope are analyzed with the Excel's LINEST function, which calculates the statistics of the line with least square fit.

In the rotational transition state of the biphenyl group, the substituents on the distal phenyl group may actually have more freedom of movements due to moving away from the Au-Cl. In other words, the methyl (21b) and $t$-butyl groups (21c) on the distal phenyl may rotate more freely when the biphenyl unit has a twist angle of near zero degree. This explanation is somewhat speculative; however there are literature precedents where external interactions cause the activation entropy to be positive. One literature example similar to this bond rotation dynamics is the report by Bergman and Raymond.[45] They examined the rotational dynamics of encapsulated guest molecules to probe the steric consequences of encapsulation within a host. Encapsulation was found to increase the $\mathrm{Ph}-\mathrm{CH}_{2}$ bond rotational barrier for ortho-substituted benzyl phosphonium guest molecules by 3 to $6 \mathrm{kcal} / \mathrm{mol}$, and also change the entropy of activation from negative to positive. Very similar parallel observations are documented here for the obiphenyl substituents in the gold(I) complexes. The precursors to gold complexes (imidazoliums $\mathbf{1 8 b}$ and 18c) showed no sign of ${ }^{1} \mathrm{H}$ NMR peak broadening at room temperature, which indicates a lower rotational barrier. However once coordinated to $\mathrm{Au}(\mathrm{I})$, the rotational barriers are raised so that coalescence is observed for the biphenyl center $\mathrm{C}-\mathrm{C}$ bond rotation. Therefore the study of the biphenyl rotational barriers support the notion that steric interactions are present between the substituents and the $\mathrm{Au}-\mathrm{Cl}$ moiety, which in turn, explains the high percent buried volumes calculated for gold complexes $\mathbf{2 1 b}$ and $\mathbf{2 1 c}$.

\section{Conclusion}

We have prepared new chiral [(NHC)Au(I)Cl] complexes featuring pairs of o-biphenyl substituents. X-Ray structure analysis was performed for two of the nine gold complexes. Large percent buried volumes are calculated for the two complexes. This indicates the proximity of the ligand substituents to the Au atom. The proximity is further corroborated by a variable temperature NMR study, which showed a free energy activation $\sim 14 \mathrm{kcal} / \mathrm{mol}$ for the biphenyl rotational barriers. Normally monosubstituted biphenyls have rotational barriers around 3-10 kcal/mol. The rotational barriers determined for these complexes are greater than usual, which indicates additional steric interactions between substituents and the $\mathrm{Au}-\mathrm{Cl}$ moiety in addition to the usual biphenyl ortho substituent interactions. Our current efforts include (1) to more precisely substantiate the correlation between steric bulk of the NHC and catalyst 
stability by estimating the half-life time of the cationic complexes under given conditions; and (2) to employ the gold complexes as enantioselective catalysts in cycloaddition reactions.

\section{Acknowledgements}

Financial support from the NSF (TUES program) and Miami University for the NMR Facility are acknowledged. We are grateful to Professor Hans Reich for assistance with the WINDNMR program. We thank Dr. Ryan Conyers for preparing the [(ADC)Au(I)Cl] complex $\mathbf{2 3}$ and Caleb Jones for preparing complex 21a.

\section{Appendix A. Supporting material}

CCDC 1049077-1049078 contain the supplementary crystallographic data for this paper. These data can be obtained free of charge from The Cambridge Crystallographic Data Centre via www.ccdc.cam.ac.uk/data_request/cif.

\section{Appendix B. Supplementary data}

Supplementary material featuring experimental details and NMR spectra related to this article can be found at http://dx.doi.org/.

\section{References}

[1] W.A. Herrmann, Angew. Chem., Int. Ed., 41 (2002) 1290-1309.

[2] N. Marion, S.P. Nolan, Chemical Society Reviews, 37 (2008) 1776-1782.

[3] S.P. Nolan, Editor, N-Heterocyclic Carbenes in Synthesis, 2006.

[4] T.J. Seiders, D.W. Ward, R.H. Grubbs, Org. Lett., 3 (2001) 3225-3228.

[5] Y. Matsumoto, K.I. Yamada, K. Tomioka, J. Org. Chem., 73 (2008) 4578-4581.

[6] A. Correa, S.P. Nolan, L. Cavallo, Topics in Current Chemistry, 302 (2011) 131-155.

[7] F. Wang, L.-j. Liu, W. Wang, S. Li, M. Shi, Coord. Chem. Rev., 256 (2012) 804-853.

[8] W.A. Herrmann, L.J. Goossen, C. Kocher, G.R.J. Artus, Angew. Chem. Int. Edit., 35 (1996) 2805-2807.

[9] C.L. Winn, F. Guillen, J. Pytkowicz, S. Roland, P. Mangeney, A. Alexakis, J. Organomet. Chem., 690 (2005) 5672-5695.

[10] Y. Sato, Y. Hinata, R. Seki, Y. Oonishi, N. Saito, Org. Lett., 9 (2007) 5597-5599.

[11] M. Nakanishi, D. Katayev, C. Besnard, E.P. Kundig, Angewandte Chemie (International ed. in English), 50 (2011) 7438-7441.

[12] B.W. Gung, R.C. Conyers, J. Wonser, Synlett, 24 (2013) 1238-1242.

[13] B.W. Gung, L.N. Bailey, D.T. Craft, C.L. Barnes, K. Kirschbaum, Organometallics, 29 (2010) 34503456.

[14] P. de Fremont, N.M. Scott, E.D. Stevens, S.P. Nolan, Organometallics, 24 (2005) 2411-2418.

[15] Y. Matsumoto, K.B. Selim, H. Nakanishi, K. Yamada, Y. Yamamoto, K. Tomioka, Tetrahedron Lett., 51 (2010) 404-406.

[16] D. Banerjee, A.K. Buzas, C. Besnard, E.P. Kundig, Organometallics, 31 (2012) 8348-8354.

[17] S. Kehrli, D. Martin, D. Rix, M. Mauduit, A. Alexakis, Chemistry - A European Journal, 16 (2010) 98909904, S9890/9891-S9890/9104. 
[18] D. Katayev, Y.-X. Jia, A.K. Sharma, D. Banerjee, C. Besnard, R.B. Sunoj, E.P. Kuendig, Chemistry - A European Journal, 19 (2013) 11916-11927.

[19] E.P. Kundig, M. Seidel Thomas, Y.-X. Jia, G. Bernardinelli, Angewandte Chemie (International ed. in English), 46 (2007) 8484-8487.

[20] A. Aranyos, D.W. Old, A. Kiyomori, J.P. Wolfe, J.P. Sadighi, S.L. Buchwald, J. Am. Chem. Soc., 121

(1999) 4369-4378.

[21] S.D. Walker, T.E. Barder, J.R. Martinelli, S.L. Buchwald, Angew. Chem. Int. Ed., 43 (2004) 1871-1876.

[22] C. Nieto-Oberhuber, S. Lopez, A.M. Echavarren, J. Am. Chem. Soc., 127 (2005) 6178-6179.

[23] S. Handa, M. Slaughter Legrande, Angewandte Chemie (International ed. in English), (2012).

[24] I. Caracelli, J. Zukerman-Schpector, E.R.T. Tiekink, Gold Bulletin (Berlin, Germany), 46 (2013) 81-89.

[25] H. Wu, S. Radomkit, J.M. O'Brien, A.H. Hoveyda, J. Am. Chem. Soc., 134 (2012) 8277-8285.

[26] L.M. Klingensmith, K.A. Nadeau, G.A. Moniz, Tetrahedron Lett., 48 (2007) 4589-4593.

[27] J. Dalmolen, M. Van der Sluis, J.W. Nieuwenhuijzen, A. Meetsma, B. De Lange, B. Kaptein, R.M. Kellogg, Q.B. Broxterman, Eur. J. Org. Chem., (2004) 1544-1557.

[28] J.A. Fernandez-Salas, M.C. Maestro, M.M. Rodriguez-Fernandez, J.L. Garcia-Ruano, I. Alonso, Org. Lett., 15 (2013) 1658-1661.

[29] J.A. Fernandez-Salas, M.M. Rodriguez-Fernandez, M.C. Maestro, J.L. Garcia-Ruano, Eur. J. Org. Chem., 2014 (2014) 5265-5272.

[30] A. Collado, A. Gomez-Suarez, A.R. Martin, A.M.Z. Slawin, S.P. Nolan, Chemical Communications (Cambridge, United Kingdom), 49 (2013) 5541-5543.

[31] A.S.K. Hashmi, D. Riedel, M. Rudolph, F. Rominger, T. Oeser, Chemistry - A European Journal, 18 (2012) 3827-3830, S3827/3821-S3827/3835.

[32] C. Conyers Ryan, W. Gung Benjamin, in, Miami University, 2013.

[33] R.C. Conyers, B.W. Gung, Chemistry - A European Journal, 19 (2013) 654-664.

[34] C.A. Tolman, Chem. Rev., 77 (1977) 313-348.

[35] L. Cavallo, A. Correa, C. Costabile, H. Jacobsen, J. Organomet. Chem., 690 (2005) 5407-5413.

[36] H. Clavier, P. Nolan Steven, Chemical communications (Cambridge, England), 46 (2010) 841-861.

[37] A. Poater, B. Cosenza, A. Correa, S. Giudice, F. Ragone, V. Scarano, L. Cavallo, Eur. J. Inorg. Chem., (2009) 1759-1766.

[38] S. Gaillard, X. Bantreil, A.M.Z. Slawin, S.P. Nolan, Dalton Transactions, (2009) 6967-6971.

[39] L. Jafarpour, E.D. Stevens, S.P. Nolan, J. Organomet. Chem., 606 (2000) 49-54.

[40] H.J. Reich, in: WinDNMR: Dynamic NMR Spectra for Windows, J. Chem. Educ. Software, 1996-2003, pp. 3D2, For an updated version see: http://www.chem.wisc.edu/areas/reich/plt/winplt.htm.

[41] A. Gomez-Suarez, R.S. Ramon, O. Songis, A.M.Z. Slawin, C.S.J. Cazin, S.P. Nolan, Organometallics, 30 (2011) 5463-5470.

[42] F. Leroux, Chembiochem, 5 (2004) 644-649.

[43] N. Isaacs, Physical Organic Chemistry, Second ed., Longman, New York, 1995.

[44] G. Bott, L.D. Field, S. Sternhell, J. Am. Chem. Soc., 102 (1980) 5618-5626.

[45] J.S. Mugridge, G. Szigethy, R.G. Bergman, K.N. Raymond, J. Am. Chem. Soc., 132 (2010) 16256-

16264. 

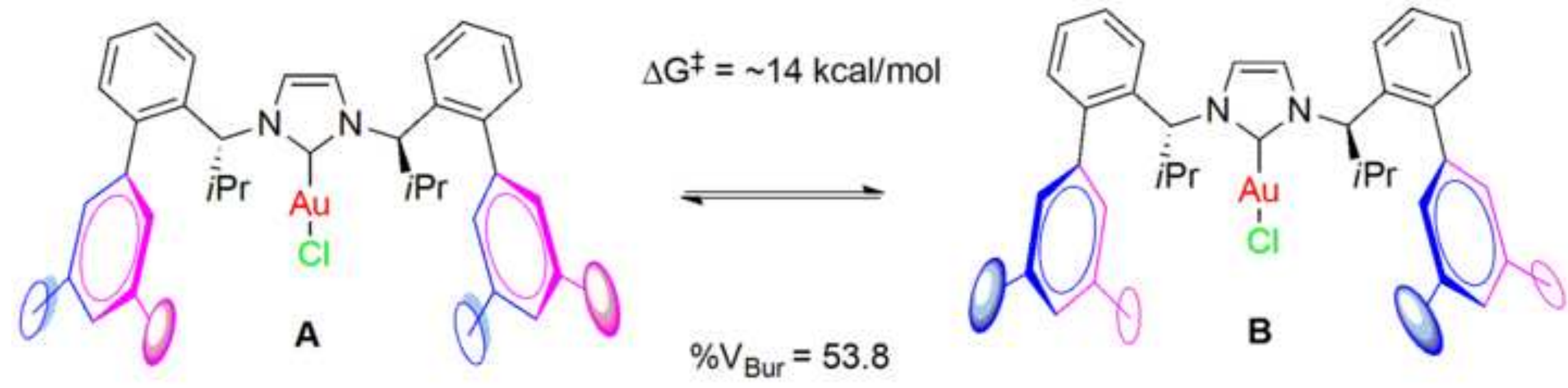